Article

\title{
Study of the Lipid Profile of ATCC and Clinical Strains of Staphylococcus aureus in Relation to Their Antibiotic Resistance
}

\author{
Carlo Bisignano ${ }^{1}$, Giovanna Ginestra ${ }^{2}\left(\mathbb{D}\right.$, Antonella Smeriglio ${ }^{2}(0)$, Erminia La Camera ${ }^{2}$, \\ Giuseppe Crisafi ${ }^{2}$, Flavio A. Franchina ${ }^{3,4,5}$, Peter Q. Tranchida ${ }^{2}$, Angela Alibrandi ${ }^{6}$, \\ Domenico Trombetta ${ }^{2}$, Luigi Mondello 2,3 (1) and Giuseppina Mandalari 2,*(1)
}

1 Department of Biomedical, Dental, Morphological and Functional Images Sciences, University of Messina, Via C. Valeria, 98125 Messina, Italy; cbisignano@unime.it

2 Department of Chemical, Biological, Pharmaceutical and Environmental Sciences, University of Messina, I-98168 Messina, Italy; gginestra@unime.it (G.G.); asmeriglio@unime.it (A.S.); elacamera@unime.it (E.L.C.); gcrisafi@unime.it (G.C.); ptranchida@unime.it (P.Q.T.); dtrombetta@unime.it (D.T.); lmondello@unime.it (L.M.)

3 Chromaleont c/o Department of Chemical, Biological, Pharmaceutical and Environmental Sciences, University of Messina, I-98168 Messina, Italy; ffranchina@unime.it

4 School of Engineering at Dartmouth College, 14 Engineering Drive, Hanover, NH 03755, USA

5 University of Liège, Molecular System Organic \& Biological Analytical Chemistry, 11 Allée du Six Août, 4000 Liège, Belgium

6 Department of Economics, Unit of Statistical and Mathematical Sciences, University of Messina, 98125 Messina, Italy; aalibrandi@unime.it

* Correspondence: gmandalari@unime.it; Tel.: +39-090-6766593; Fax: +39-090-6766474

Received: 26 February 2019; Accepted: 29 March 2019; Published: 2 April 2019

\begin{abstract}
A number of reports have indicated a relationship between bacterial resistance to antibiotics and their lipid composition. In the present study, we characterized the lipid profiles of American Type Culture Collection (ATCC) and clinical strains of Staphylococcus aureus and its correlation with antibiotic resistance and hydrophobicity. The following strains were used: S. aureus ATCC 6538P, S. aureus ATCC 43300 (MRSA), seven clinical strains from the pharynges, two strains from duodenal ulcers, four strains from hip prostheses, and one strain from the conjunctiva. Lipid-related differentiation was observed across the $S$. aureus strains: the higher abundance of anteiso-pentadecanoic acid (anteiso- $\mathrm{C}_{15: 0}$ ) and anteiso-heptadecanoic acid (anteiso- $\mathrm{C}_{17: 0}$ ), followed by iso-pentadecanoic acid (iso- $\mathrm{C}_{15: 0}$ ), suggested that these were common lipids. Iso-tridecanoic acid (iso- $\mathrm{C}_{13: 0}$ ) and anteiso-tridecanoic acid (anteiso- $\mathrm{C}_{13: 0}$ ), iso-hexadecanoic acid (iso- $\mathrm{C}_{16: 0}$ ) and anteiso-hexadecanoic acid (anteiso- $\left.\mathrm{C}_{16: 0}\right)$, and all forms of octadecanoic acid $\left(\mathrm{C}_{18: 0}\right)$ were usually detected in low abundance. Strains isolated from pharynges showed the highest ratio of branched/straight chains. A distinction in two clusters based on the amount and type of bacterial lipids identified was obtained, which correlated to the antibiotic resistance, the strains origin, and the cell-surface hydrophobicity. We report a potential correlation between the lipid profile of $S$. aureus strains, site of infection, antibiotic resistance, and cell-surface hydrophobicity. These results, which still need further insights, could be a first step to identifying antibiotic resistance in response to environmental adaptation.
\end{abstract}

Keywords: Staphylococcus aureus; lipids; antibiotic resistance; hydrophobicity; ATCC strains; clinical strains 


\section{Introduction}

Amongst the significant Gram-positive human pathogens, Staphyloccus aureus (S. aureus) and methicillin-resistant S. aureus (MRSA) play an important role, being responsible for a variety of infections, such as skin, respiratory, and bone joint infection, as well as endocarditis, bacteremia, and toxic shock syndrome [1]. The ability of $S$. aureus to produce a biofilm makes this strain responsible for infections of implanted medical devices, wounds associated infections, cystic fibrosis, and otitis media [2-4]. Due to the increased spread of multi-drug resistance, growing interest has been focused on the identification of novel antimicrobial agents against $S$. aureus and MRSA: a number of natural compounds and antimicrobial peptides have been identified [5-7]. Over the last few decades, understanding the mechanisms involved in the adaptation of microbial cells to environmental conditions has gained much interest [8]. Exposure to specific antimicrobials at sub-lethal concentrations could result in acquired resistance $[9,10]$.

The relation between bacterial resistance to different antibiotics and lipid composition of these organisms has been reported: Yehia et al. [11] have demonstrated that antibiotic treatment determined a genetic alteration of the lipid biosynthesis in Pseudomonas aeruginosa, with an effect on exopolysaccharides production. The lipid profiles of three closely related strains of Escherichia coli were monitored using high resolution mass spectrometry: results showed a shift in the lipid distribution that correlated to the antibiotic exposure [12]. Furthermore, changes in the lipopolysaccharide profile of clinical isolates of Porphyromonas gingivalis correlated with changes in colony morphology and resistance to polymyxin $B$ in both healthy and periodontitis patients: this trend was associated with differences in bacterial virulence and progression of periodontitis [13]. The characterization of cell membrane parameters of clinical isolates of $S$. aureus with different susceptibility to the alpha-melanocyte stimulating hormone demonstrated the presence of a rigid membrane. Higher amounts of the cationic phospholipid were detected in the strains resistant to the peptide [7].

We have previously characterized the lipid profiles of five different strains of Gram-positive and Gram-negative bacteria using a rapid sample preparation method and fast comprehensive two-dimensional gas chromatography in combination with mass spectrometry (GC $\times$ GC-MS) [14]. In the present paper, we report the characterization of the lipid profiles of ATCC and clinical strains of S. aureus and their correlation with antibiotic resistance and hydrophobicity: the origin of the clinical strains was also be evaluated in relation to drug resistance.

\section{Results}

\subsection{Bacterial Lipid Profiles}

The identification of BAMEs and their relative abundance across the tested strains is reported in Table 1. Lipid-related differentiation across the various $S$. aureus strains was observed: the higher abundance of anteiso-pentadecanoic acid (anteiso- $\mathrm{C}_{15: 0}$ ) and anteiso-heptadecanoic acid (anteiso- $\mathrm{C}_{17: 0}$ ), followed by iso-pentadecanoic acid (iso- $\mathrm{C}_{15: 0}$ ), suggested that these lipids were common and could be detected in all strains. However, other lipids, including iso-tridecanoic acid (iso- $\mathrm{C}_{13: 0}$ ) and anteiso-tridecanoic acid (anteiso- $\mathrm{C}_{13: 0}$ ), iso-hexadecanoic acid (iso- $\mathrm{C}_{16: 0}$ ) and anteiso-hexadecanoic acid (anteiso- $\left.\mathrm{C}_{16: 0}\right)$, and all forms of octadecanoic acid $\left(\mathrm{C}_{18: 0}\right)$, were usually detected in low abundance and did not appear in all strains. Strangely, no iso- $\mathrm{C}_{15: 0}$ branched chain fatty acid was detected in strain 98 isolated from conjunctiva. The lipid composition of strain 530 was unique, with the lowest concentration of the most abundant fatty acid present, anteiso- $\mathrm{C}_{15: 0}$, and the highest concentration of the polyunsaturated $C_{18: 3}(n-3)$. Table 2 reports some features of the lipid profiles detected in the bacterial strains. Interestingly, strains isolated from pharynges showed the highest ratio of branched/straight chain, with the exception of strain 530, followed by strain 8 and the MRSA ATCC strain 43300 . The ratio iso/anteiso varied between 0.119 (strain 531) and 0.418 (strain 3), whereas strain 530 showed the highest ratio of unsaturated versus saturated fatty acids. 
Table 1. Bacterial fatty acid methyl esters (BAMEs) quantified (\%) in bacterial strains under study by Gas Chromatography-Flame Ionization Detector (GC-FID) analysis. n.d.= not detected; $\mathrm{tr}=\mathrm{traces}$.

\begin{tabular}{|c|c|c|c|c|c|c|c|c|}
\hline \multirow{2}{*}{ BAMEs } & \multicolumn{8}{|c|}{ Bacterial Strain } \\
\hline & 531 & 26 & 808 & 43300 & 8 & 814 & 530 & 14 \\
\hline Me. $C_{6: 0}$ & n.d. & n.d. & n.d. & n.d. & n.d. & n.d. & n.d. & 0.11 \\
\hline Me. $C_{10: 0}$ & n.d. & n.d. & n.d. & n.d. & n.d. & n.d. & n.d. & n.d. \\
\hline Me. $C_{11: 0}$ & n.d. & n.d. & n.d. & n.d. & n.d. & n.d. & n.d. & n.d. \\
\hline Me. $C_{12: 0}$ & n.d. & n.d. & n.d. & 0.05 & n.d. & n.d. & 0.49 & n.d. \\
\hline Me. $C_{13: 0}$ iso & 0.05 & 0.21 & n.d. & 0.05 & n.d. & 0.10 & 0.29 & n.d. \\
\hline Me. $C_{13: 0}$ & n.d. & n.d. & n.d. & n.d. & n.d. & n.d. & n.d. & n.d. \\
\hline Me. $C_{13: 0}$ anteiso & 0.16 & 0.03 & n.d. & 0.06 & n.d. & n.d. & 0.10 & n.d. \\
\hline Me. $C_{14: 0}$ iso & 0.86 & 0.65 & 0.97 & 0.49 & 1.32 & 1.71 & 0.78 & 0.84 \\
\hline Me. $C_{14: 0}$ & 0.15 & 0.08 & 0.21 & 0.19 & 0.33 & 0.39 & 1.74 & 0.65 \\
\hline Me. $C_{15: 0}$ iso & 3.66 & 4.83 & 6.81 & 5.84 & 9.41 & 10.23 & 4.97 & 5.69 \\
\hline Me. $C_{15: 0}$ anteiso & 58.98 & 50.98 & 52.97 & 52.30 & 56.04 & 49.95 & 33.32 & 48.42 \\
\hline Me. $C_{15: 0}$ & 0.03 & 0.05 & n.d. & $\operatorname{tr}$ & n.d. & n.d. & 0.10 & n.d. \\
\hline Me. $C_{16: 0}$ anteiso & n.d. & 2.08 & n.d. & n.d. & n.d. & n.d. & n.d. & n.d. \\
\hline Me. $\mathrm{C}_{16: 0}$ iso & 2.18 & n.d. & 2.20 & 1.23 & 2.00 & 2.70 & 2.82 & 1.98 \\
\hline Me. $C_{16: 0}$ & 1.44 & 0.95 & 1.93 & 1.63 & 2.39 & 2.35 & 1.70 & 3.73 \\
\hline Me. $C_{17: 0}$ iso & 2.33 & 4.24 & 4.13 & 3.80 & 4.13 & 4.40 & 4.20 & 3.65 \\
\hline Me. $C_{17: 0}$ anteiso & 22.98 & 22.64 & 18.73 & 21.18 & 14.16 & 13.76 & 17.25 & 21.04 \\
\hline Me. $C_{17: 0}$ & 0.08 & 0.16 & n.d. & 0.08 & 0.10 & 0.15 & 1.60 & n.d. \\
\hline Me. $C_{18: 0}$ iso & 0.49 & 1.13 & 0.80 & 0.50 & 0.63 & 0.83 & 1.39 & 0.88 \\
\hline Me. $C_{18: 0}$ & 2.68 & 3.14 & 4.52 & 6.10 & 4.50 & 4.41 & 6.15 & 6.17 \\
\hline Me. $C_{18: \ln 6}$ & n.d. & n.d. & n.d. & n.d. & n.d. & 0.97 & n.d. & n.d. \\
\hline Me. $C_{18: \ln 9}$ & 0.18 & n.d. & 1.93 & n.d. & n.d. & n.d. & 0.78 & n.d. \\
\hline Me. $C_{18: \ln 7}$ & n.d. & n.d. & n.d. & n.d. & n.d. & 0.06 & 0.12 & n.d. \\
\hline Me. $C_{18: \ln 3}$ & n.d. & n.d. & n.d. & n.d. & n.d. & n.d. & n.d. & n.d. \\
\hline Me. $C_{18: \ln 11}$ & 0.05 & 0.35 & n.d. & n.d. & n.d. & n.d. & n.d. & n.d. \\
\hline Me. $C_{19: 0}$ iso & 0.50 & 1.51 & 1.08 & 1.08 & 0.94 & n.d. & 1.90 & 0.90 \\
\hline Me. $C_{18: 2 n 6}$ & n.d. & n.d. & n.d. & n.d. & n.d. & 0.83 & n.d. & n.d. \\
\hline Me. $C_{18: 2 n 9}$ & 0.23 & n.d. & n.d. & n.d. & n.d. & n.d. & n.d. & n.d. \\
\hline Me. $C_{18: 3 n 3}$ & n.d. & n.d. & n.d. & n.d. & n.d. & n.d. & 12.04 & n.d. \\
\hline Me. $C_{19: 0}$ anteiso & 2.31 & 4.64 & 2.63 & 3.51 & 1.99 & 1.53 & 4.24 & 3.55 \\
\hline Me. $C_{19: 0}$ iso & n.d. & n.d. & n.d. & n.d. & n.d. & 0.93 & 0,36 & n.d. \\
\hline Me. $C_{19: 0}$ & 0.05 & 0.20 & n.d. & 0.14 & 0.27 & 0.36 & n.d. & 0.16 \\
\hline Me. $C_{19: 3 n 3}$ & n.d. & n.d. & n.d. & n.d. & n.d. & 2.70 & n.d. & n.d. \\
\hline Me. $C_{20: 0}$ & 0.61 & 1.78 & 1.08 & 1.61 & 1.79 & 1.53 & 3.10 & 1.90 \\
\hline Me. $C_{20: 0}$ iso & n.d. & 0.36 & n.d. & 0.09 & n.d. & 0.12 & 0.31 & 0.31 \\
\hline Me. $C_{20: 1 n 7}$ & n.d. & n.d. & n.d. & n.d. & n.d. & n.d. & n.d. & n.d. \\
\hline Me. $C_{20: 1 n 9}$ & n.d. & n.d. & n.d. & 0.06 & n.d. & n.d. & n.d. & n.d. \\
\hline Me. $C_{21: 0}$ & n.d. & n.d. & n.d. & n.d. & n.d. & n.d. & n.d. & n.d. \\
\hline Me. $C_{21: 0}$ iso & n.d. & n.d. & n.d. & n.d. & n.d. & n.d. & 0.26 & n.d. \\
\hline Me. $C_{22: 0}$ & n.d. & n.d. & n.d. & n.d. & n.d. & n.d. & n.d. & n.d. \\
\hline Me. $C_{22: 1 n 9}$ & n.d. & n.d. & n.d. & n.d. & n.d. & n.d. & n.d. & n.d. \\
\hline Me. $C_{22: 1 n 11}$ & n.d. & n.d. & n.d. & n.d. & n.d. & n.d. & n.d. & n.d. \\
\hline Me. $C_{24: 0}$ & n.d. & n.d. & n.d. & n.d. & n.d. & n.d. & n.d. & n.d. \\
\hline \multirow{2}{*}{ MEs } & \multicolumn{8}{|c|}{ Bacterial Strains } \\
\hline & 550 & 32 & $6538 \mathrm{P}$ & 526 & 6 & 3 & 98 & 84 \\
\hline Me. $C_{6: 0}$ & n.d. & n.d. & n.d. & n.d. & n.d. & n.d. & n.d. & n.d. \\
\hline
\end{tabular}


Table 1. Cont

\begin{tabular}{|c|c|c|c|c|c|c|c|c|}
\hline \multirow{2}{*}{ BAMEs } & \multicolumn{8}{|c|}{ Bacterial Strain } \\
\hline & 531 & 26 & 808 & 43300 & 8 & 814 & 530 & 14 \\
\hline Me. $C_{10: 0}$ & n.d. & n.d. & n.d. & n.d. & 0.09 & n.d. & 0.11 & n.d. \\
\hline Me. $C_{11: 0}$ & n.d. & n.d. & n.d. & n.d. & n.d. & n.d. & n.d. & n.d. \\
\hline Me. $C_{12: 0}$ & 0.13 & 0.03 & 0.27 & 0.03 & 0.02 & 0.06 & 0.09 & 0.07 \\
\hline Me. $C_{13: 0}$ iso & 0.17 & 0.09 & 0.14 & 0.29 & 0.10 & 0.22 & 0.12 & 0.13 \\
\hline Me. $C_{13: 0}$ & n.d. & n.d. & n.d. & n.d. & n.d. & n.d. & n.d. & n.d. \\
\hline Me. $C_{13: 0}$ anteiso & 0.50 & 0.06 & 0.11 & 0.06 & 0.06 & 0.06 & 0.07 & 0,06 \\
\hline Me. $\mathrm{C}_{14: 0}$ iso & 1.24 & 0.64 & 0.75 & 1.16 & 0.56 & 1.22 & 0.79 & 1.16 \\
\hline Me. $C_{14: 0}$ & 0.36 & 0.16 & 0.43 & 0.26 & 0.18 & 0.18 & 0.29 & 0.22 \\
\hline Me. $C_{15: 0}$ iso & 6.53 & 5.84 & 6.00 & 5.79 & 9.38 & 9.11 & n.d. & 9.24 \\
\hline Me. $C_{15: 0}$ anteiso & 44.53 & 44.42 & 45.04 & 47.80 & 41.91 & 38.35 & 47.93 & 43.99 \\
\hline Me. $\mathrm{C}_{15: 0}$ & 0.09 & 0.03 & 0.03 & 0.14 & 0.02 & n.d. & 0.01 & 0.03 \\
\hline Me. $C_{16: 0}$ anteiso & n.d. & n.d. & 1.81 & n.d. & n.d. & n.d. & n.d. & n.d. \\
\hline Me. $\mathrm{C}_{16: 0}$ iso & 2.47 & 1.20 & n.d. & 2.49 & 1.57 & 2.70 & 1.61 & 2.49 \\
\hline Me. $C_{16: 0}$ & 3.41 & 1.60 & 4.38 & 4.10 & 1.91 & 1.98 & 2.20 & 2.13 \\
\hline Me. $C_{17: 0}$ iso & 4.44 & 4.54 & 3.70 & 3.93 & 6.87 & 7.35 & 5.27 & 6.01 \\
\hline Me. $C_{17: 0}$ anteiso & 18.08 & 20.76 & 19.84 & 18.49 & 19.20 & 17.35 & 20.95 & 18.06 \\
\hline Me. $C_{17: 0}$ & n.d. & 0.16 & 0.22 & 0.11 & 0.08 & 0.09 & 0.11 & 2.03 \\
\hline Me. $C_{18: 0}$ iso & 1.29 & 0.74 & 0.78 & 1.12 & 0.80 & 1.46 & 0.64 & 0.92 \\
\hline Me. $C_{18: 0}$ & 7.82 & 7.53 & 7.50 & 7.32 & 6.53 & 7.13 & 5.22 & 6.45 \\
\hline Me. $C_{18: 1 n 6}$ & n.d. & n.d. & n.d. & n.d. & n.d. & n.d. & n.d. & n.d. \\
\hline Me. $C_{18: 1 n 9}$ & n.d. & 0.19 & n.d. & n.d. & 0.57 & 1.29 & 0.60 & 0.92 \\
\hline Me. $C_{18: 1 n 7}$ & n.d. & 0.04 & n.d. & n.d. & 0.06 & 0.13 & 0.09 & 0.07 \\
\hline Me. $C_{18: 1 n 3}$ & n.d. & 0.01 & n.d. & n.d. & n.d. & n.d. & n.d. & n.d. \\
\hline Me. $C_{18: 1 n 11}$ & n.d. & n.d. & n.d. & n.d. & n.d. & n.d. & n.d. & n.d. \\
\hline Me. $C_{19: 0}$ iso & 1.46 & 1.74 & 1.19 & n.d. & 2.13 & 2.16 & 1.11 & 1.03 \\
\hline Me. $C_{18: 2 n 6}$ & n.d. & n.d. & n.d. & n.d. & n.d. & n.d. & n.d. & n.d. \\
\hline Me. $C_{18: 2 n 9}$ & n.d. & n.d. & n.d. & n.d. & n.d. & n.d. & n.d. & n.d. \\
\hline Me. $C_{18: 3 n 3}$ & n.d. & $\operatorname{tr}$ & n.d. & n.d. & n.d. & n.d. & n.d. & n.d. \\
\hline Me. $C_{19: 0}$ anteiso & 3.92 & 5.22 & 4.19 & 3.67 & 3.72 & 3.71 & 3.20 & 2.36 \\
\hline Me. $C_{19: 0}$ iso & 0.22 & n.d. & n.d. & 1.11 & n.d. & n.d. & n.d. & n.d. \\
\hline Me. $C_{19: 0}$ & n.d. & 0.34 & 0.13 & 0.09 & 0.16 & 0.36 & 0.13 & 0.22 \\
\hline Me. $C_{19: 3 n 3}$ & n.d. & n.d. & n.d. & n.d. & n.d. & n.d. & n.d. & n.d. \\
\hline Me. $C_{20: 0}$ & 2.89 & 4.01 & 2.15 & 1.71 & 3.28 & 4.15 & 1.84 & 1.90 \\
\hline Me. $C_{20: 0}$ iso & 0.46 & 0.21 & 0.26 & 0.33 & 0.22 & 0.50 & 0.20 & 0.18 \\
\hline Me. $C_{20: 1 n 7}$ & n.d. & 0.03 & n.d. & n.d. & n.d. & n.d. & n.d. & n.d. \\
\hline Me. $C_{20: 1 n 9}$ & n.d. & 0.07 & n.d. & n.d. & n.d. & n.d. & n.d. & n.d. \\
\hline Me. $C_{21: 0}$ & n.d. & 0.25 & n.d. & n.d. & 0.16 & 0.31 & n.d. & 0.18 \\
\hline Me. $C_{21: 0}$ iso & n.d. & 0.10 & 1.08 & n.d. & 0.17 & 0.14 & n.d. & 0.18 \\
\hline Me. $C_{22: 0}$ & n.d. & n.d. & n.d. & n.d. & 0.26 & n.d. & n.d. & n.d. \\
\hline Me. $C_{22: 1 n 9}$ & n.d. & n.d. & n.d. & n.d. & n.d. & n.d. & n.d. & n.d. \\
\hline Me. $C_{22: 1 n 11}$ & n.d. & n.d. & n.d. & n.d. & n.d. & n.d. & n.d. & n.d. \\
\hline Me. $C_{24: 0}$ & n.d. & n.d. & n.d. & n.d. & n.d. & n.d. & n.d. & n.d. \\
\hline
\end{tabular}


Table 2. Features of lipid profiling identified in the selected bacterial strains.

\begin{tabular}{|c|c|c|c|c|}
\hline Bacterial Strain & Branched Chain/Straight Chain & Iso/Anteiso & UFAs/SFAs & FA Chain Length Ranges \\
\hline 531 & 17.179 & 0.119 & 0.005 & $\mathrm{C} 13-\mathrm{C} 20$ \\
\hline 26 & 13.932 & 0.161 & 0.004 & $\mathrm{C} 13-\mathrm{C} 20$ \\
\hline 581 & 9.777 & 0.162 & 0.011 & $\mathrm{C} 11-\mathrm{C} 24$ \\
\hline 808 & 9.333 & 0.215 & 0.020 & $\mathrm{C} 14-\mathrm{C} 20$ \\
\hline ATCC 43300 & 9.125 & 0.170 & 0.001 & $\mathrm{C} 12-\mathrm{C} 20$ \\
\hline 814 & 6.281 & 0.322 & 0.048 & $\mathrm{C} 13-\mathrm{C} 20$ \\
\hline 530 & 2.595 & 0.314 & 0.150 & $\mathrm{C} 12-\mathrm{C} 21$ \\
\hline 14 & 6.854 & 0.195 & 0.000 & C6-C20 \\
\hline 550 & 5.803 & 0.273 & 0.000 & $\mathrm{C} 12-\mathrm{C} 20$ \\
\hline 526 & 6.273 & 0.232 & 0.000 & C12-C20 \\
\hline 6 & 6.512 & 0.336 & 0.006 & $\mathrm{C} 10-\mathrm{C} 22$ \\
\hline 3 & 5.376 & 0.418 & 0.014 & C12-C21 \\
\hline 98 & 7.667 & 0.135 & 0.008 & C10-C20 \\
\hline
\end{tabular}

Iso/Anteiso represents the ratio iso/anteiso (branched chain). UFA/sFAs represents the ratio unsaturated fatty acids (UFAs)/saturated fatty acids (sFAs). FA: fatty acid.

The dendrogram reported in Figure 1A shows the distinction in two clusters (red and green) of the tested strains in relation to the amounts of bacterial lipids identified. 


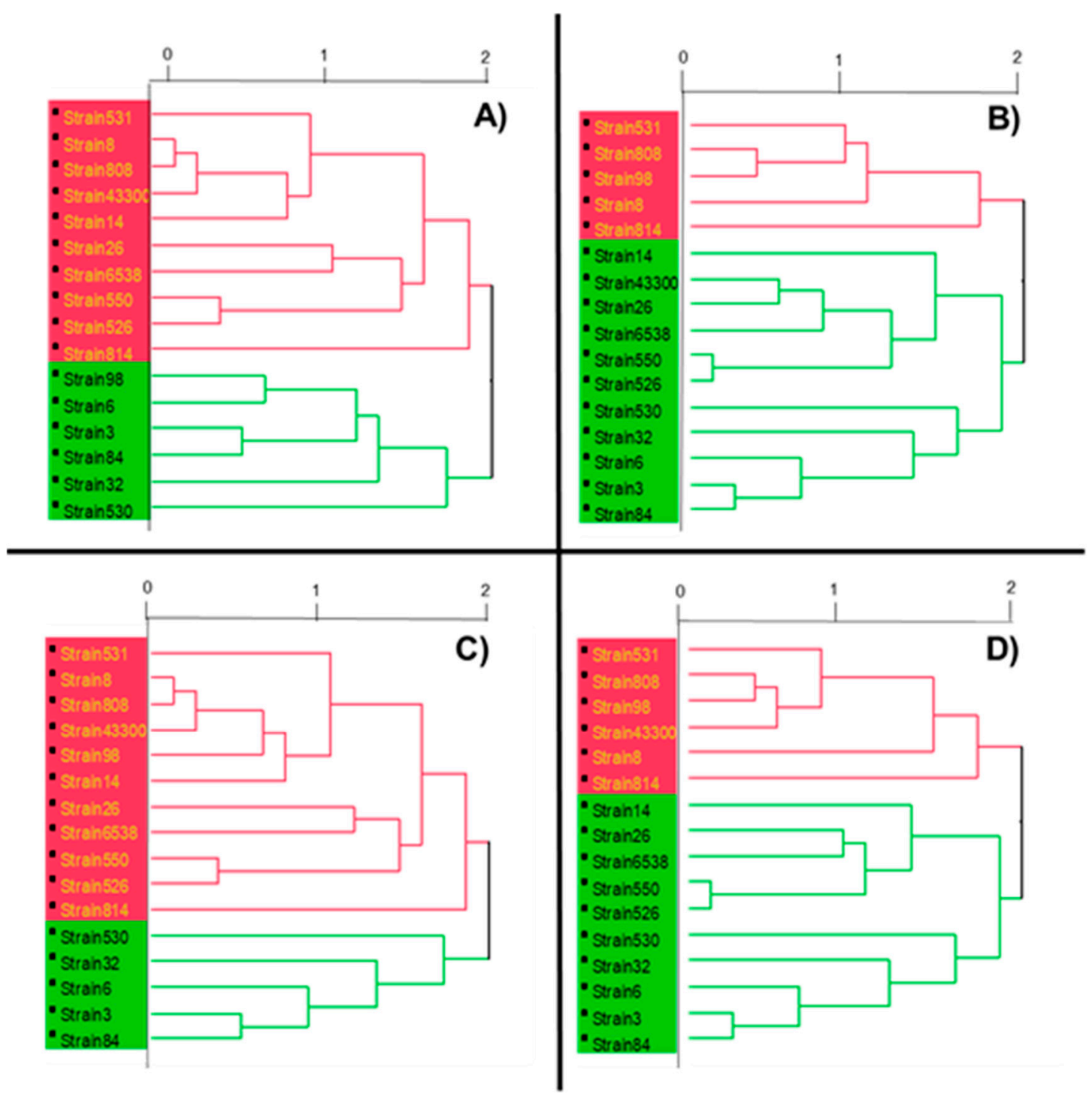

Figure 1. Dendrograms constructed using the Ward method for the cluster analysis of fatty acid from ATCC and clinical strains of Staphylococcus aureus: (A) fatty acid; (B) fatty acid and antibiotic susceptibility profile; (C) fatty acid and hydrophobicity index; (D) fatty acid, antibiotic susceptibility profile, and hydrophobicity index. The horizontal axis of the dendrogram represents the distance or dissimilarity between clusters. The vertical axis represents the objects and clusters. The horizontal axis is calculated as "even spacing", so 2 represents the maximal distance, 1 the intermediate distance and 0 no distance.

\subsection{Antibiotic Resistance}

The classification of the strains into "susceptible standard dosing regimen" (S), "susceptible increased exposure" (I), and "resistant" (R) to the selected antibiotics according to Reference [15] is reported in Table 3. Results of negative controls indicated the complete absence of inhibition for all the strains (results not shown). All tested strains were susceptible to vancomycin, teicoplanin (with the exception of strain 6), and linezolid, whereas resistance was observed against benzyl penicillin.

The minimum inhibitory concentration (MIC) and the minimum bactericidal concentration (MBC) values of vancomycin and teicoplanin are shown in Table 4 . The detected $M B C$ values were in the range between 0.31 and $1.25 \mu \mathrm{g} / \mathrm{mL}$ and 0.15 and $1.25 \mu \mathrm{g} / \mathrm{mL}$ for vancomycin and teicoplanin, respectively. 
Table 3. Strains classification into "susceptible standard dosing regimen" (S), "susceptible increased exposure" (I), and "resistant" (R) to the selected antibiotics. Values represent the mean of three determinations $\pm S D$. R indicates resistance.

\begin{tabular}{|c|c|c|c|c|c|c|c|c|c|c|c|c|c|c|}
\hline Strain & Oxacillin & Cefoxitin & Clarithromycin & Vancomycin & Levofloxacin & Teicoplanin & Tetracycline & Erythromycin & Gentamicin & Clindamycin & Trimethoprim-Sulfamethoxazole & Rifampicin & Linezolid & Benzylpenicillin \\
\hline 8 & $\mathrm{~s}$ & $\mathrm{~s}$ & I & $\mathrm{s}$ & $\mathrm{s}$ & $\mathrm{s}$ & $\mathrm{s}$ & $\mathrm{s}$ & $\mathrm{s}$ & $\mathrm{s}$ & $\mathrm{R}$ & $\mathrm{I}$ & $\mathrm{s}$ & $\mathrm{R}$ \\
\hline 98 & $\mathrm{~s}$ & $\mathrm{R}$ & $\mathrm{I}$ & $\mathrm{s}$ & $\mathrm{s}$ & $\mathrm{s}$ & $\mathrm{I}$ & $\mathrm{s}$ & $\mathrm{R}$ & $\mathrm{R}$ & $\mathrm{R}$ & $\mathrm{R}$ & $\mathrm{s}$ & $\mathrm{R}$ \\
\hline 6 & $\mathrm{R}$ & $\mathrm{s}$ & $\mathrm{I}$ & $\mathrm{s}$ & $\mathrm{s}$ & $\mathrm{R}$ & $\mathrm{s}$ & $\mathrm{R}$ & $\mathrm{s}$ & $\mathrm{I}$ & $\mathrm{s}$ & $\mathrm{s}$ & $\mathrm{s}$ & $\mathrm{R}$ \\
\hline ATCC 43300 & $\mathrm{R}$ & $\mathrm{R}$ & $\mathrm{R}$ & $\mathrm{s}$ & $\mathrm{s}$ & $\mathrm{s}$ & $\mathrm{s}$ & $\mathrm{R}$ & $\mathrm{s}$ & $\mathrm{R}$ & $\mathrm{s}$ & $\mathrm{s}$ & $\mathrm{s}$ & $\mathrm{R}$ \\
\hline 84 & $\mathrm{~s}$ & $\mathrm{~s}$ & $\mathrm{R}$ & $\mathrm{s}$ & $\mathrm{s}$ & $\mathrm{s}$ & $\mathrm{s}$ & $\mathrm{R}$ & $\mathrm{s}$ & I & $\mathrm{s}$ & $\mathrm{s}$ & $\mathrm{s}$ & $\mathrm{R}$ \\
\hline 530 & $\mathrm{R}$ & $\mathrm{R}$ & $\mathrm{I}$ & $\mathrm{s}$ & $\mathrm{s}$ & $\mathrm{s}$ & $\mathrm{s}$ & $\mathrm{s}$ & $\mathrm{s}$ & $\mathrm{I}$ & $\mathrm{R}$ & $\mathrm{s}$ & $\mathrm{s}$ & $\mathrm{R}$ \\
\hline 32 & $\mathrm{~s}$ & $\mathrm{~s}$ & $\mathrm{R}$ & $\mathrm{s}$ & $\mathrm{s}$ & $\mathrm{s}$ & $\mathrm{s}$ & $\mathrm{R}$ & $\mathrm{s}$ & $\mathrm{s}$ & $\mathrm{s}$ & $\mathrm{s}$ & $\mathrm{s}$ & $\mathrm{R}$ \\
\hline 808 & $\mathrm{~s}$ & $\mathrm{~s}$ & I & $\mathrm{s}$ & $\mathrm{s}$ & $\mathrm{s}$ & $\mathrm{s}$ & $\mathrm{s}$ & $\mathrm{s}$ & $\mathrm{s}$ & $\mathrm{s}$ & $\mathrm{s}$ & $\mathrm{s}$ & $\mathrm{R}$ \\
\hline ATCC 6538P & $\mathrm{s}$ & $\mathrm{s}$ & $\mathrm{I}$ & $\mathrm{s}$ & $\mathrm{s}$ & $\mathrm{s}$ & $\mathrm{s}$ & $\mathrm{s}$ & $\mathrm{s}$ & $\mathrm{S}$ & $\mathrm{S}$ & $\mathrm{s}$ & $\mathrm{s}$ & $\mathrm{R}$ \\
\hline 3 & $\mathrm{~s}$ & $\mathrm{~s}$ & $\mathrm{I}$ & $\mathrm{s}$ & $\mathrm{s}$ & $\mathrm{s}$ & $\mathrm{s}$ & $\mathrm{s}$ & $\mathrm{s}$ & I & $\mathrm{s}$ & $\mathrm{s}$ & $\mathrm{s}$ & $\mathrm{R}$ \\
\hline 814 & $\mathrm{R}$ & $\mathrm{s}$ & $\mathrm{I}$ & $\mathrm{s}$ & $\mathrm{s}$ & $\mathrm{s}$ & $\mathrm{s}$ & $\mathrm{I}$ & $\mathrm{s}$ & I & $\mathrm{s}$ & $\mathrm{s}$ & $\mathrm{s}$ & $\mathrm{R}$ \\
\hline 14 & $\mathrm{~s}$ & $\mathrm{~s}$ & $\mathrm{I}$ & $\mathrm{s}$ & $\mathrm{s}$ & $\mathrm{s}$ & $\mathrm{s}$ & $\mathrm{R}$ & $\mathrm{s}$ & $\mathrm{I}$ & $\mathrm{s}$ & $\mathrm{s}$ & $\mathrm{s}$ & $\mathrm{R}$ \\
\hline 26 & $\mathrm{~s}$ & $\mathrm{~s}$ & I & $\mathrm{s}$ & $\mathrm{s}$ & $\mathrm{s}$ & $\mathrm{R}$ & $\mathrm{s}$ & $\mathrm{s}$ & $\mathrm{S}$ & $\mathrm{R}$ & $\mathrm{s}$ & $\mathrm{S}$ & $\mathrm{R}$ \\
\hline 526 & $\mathrm{~s}$ & $\mathrm{~s}$ & $\mathrm{I}$ & $\mathrm{s}$ & $\mathrm{s}$ & $\mathrm{s}$ & $\mathrm{s}$ & $\mathrm{s}$ & $\mathrm{R}$ & $\mathrm{I}$ & $\mathrm{s}$ & $\mathrm{s}$ & $\mathrm{s}$ & $\mathrm{R}$ \\
\hline 550 & $R$ & $\mathrm{~s}$ & I & $\mathrm{s}$ & $\mathrm{s}$ & $\mathrm{s}$ & $\mathrm{s}$ & $\mathrm{s}$ & $\mathrm{s}$ & $\mathrm{s}$ & $\mathrm{s}$ & $\mathrm{s}$ & $\mathrm{s}$ & $\mathrm{R}$ \\
\hline 531 & $\mathrm{~s}$ & $\mathrm{~s}$ & $\mathrm{I}$ & $\mathrm{s}$ & $\mathrm{s}$ & $\mathrm{s}$ & $\mathrm{s}$ & $\mathrm{s}$ & $\mathrm{R}$ & $\mathrm{R}$ & $\mathrm{s}$ & $\mathrm{s}$ & $\mathrm{s}$ & $\mathrm{R}$ \\
\hline
\end{tabular}


Table 4. MICs $\left(\mu \mathrm{g} \mathrm{mL}^{-1}\right)$ and MBC $\left(\mu \mathrm{g} \mathrm{mL}^{-1}\right)$ of vancomycin and teicoplanin against ATCC and clinical strains of $S$. aureus.

\begin{tabular}{ccccc}
\hline Strain & \multicolumn{2}{c}{ Vancomycin } & \multicolumn{2}{c}{ Teicoplanin } \\
\hline 8 & MIC & MBC & MIC & MBC \\
\hline 98 & $0.62-1.25$ & 1.25 & 0.31 & 0.31 \\
\hline 6 & 0.31 & 0.31 & 0.31 & 0.31 \\
\hline ATCC 43300 & 0.31 & 0.62 & 1.25 & 1.25 \\
\hline 84 & 0.31 & 0.62 & 0.31 & 0.31 \\
\hline 530 & 0.62 & 0.62 & 0.62 & 1.25 \\
\hline 32 & $0.31-0.62$ & 0.62 & $0.31-0.62$ & 0.62 \\
\hline 808 & 0.62 & 0.62 & 0.31 & 0.31 \\
\hline ATCC $6538 \mathrm{P}$ & 0.31 & 0.31 & 0.15 & 0.15 \\
\hline 3 & 0.31 & 0.62 & 0.15 & 0.15 \\
\hline 814 & 0.31 & 0.62 & $0.15-0.31$ & 0.31 \\
\hline 14 & 0.62 & 0.62 & 0.62 & 1.25 \\
\hline 26 & 0.31 & 0.31 & $0.15-0.31$ & 0.31 \\
\hline 526 & 0.62 & 0.62 & 0.31 & 0.62 \\
\hline 550 & 0.31 & 0.62 & 0.31 & 0.62 \\
\hline 531 & 0.31 & 0.62 & 0.31 & 1.25 \\
\hline & 0.31 & 0.31 & $0.078-0.15$ & 0.62 \\
\hline
\end{tabular}

\subsection{Cell-Surface Hydrophobicity}

The bacteria tested showed a broad range of cell-surface hydrophobicity (expressed as hydrophobicity index \%, Table 5). The lowest hydrophobicity indices (\%) were obtained with the MRSA strains 526, 531, and 550 obtained from the pharynges. As for the lipid profile, strain 530 was significantly different from other strains isolated from pharynges, with higher hydrophobicity index. The two strains of $S$. aureus obtained from duodenal ulcers (strains 8,14 ) showed a very similar hydrophobicity index, as well as strains 26 and 814 obtained from the pharynges. The highest hydrophobicity index was obtained with the ATCC strain 6538P, followed by the clinical strains isolated from the pharynges $(3,6$, and 32$)$.

Table 5. Cell-surface hydrophobicity (expressed as \% hydrophobicity index) of ATCC and clinical strains of $S$. aureus. Values represent the mean of three determinations.

\begin{tabular}{cc}
\hline Strain & Hydrophobicity Index (\%) \\
\hline 8 & $23.89 \pm 1.7$ \\
98 & $62.76 \pm 2.5$ \\
6 & $63.29 \pm 1.9$ \\
ATCC 43300 & $57.23 \pm 2.4$ \\
84 & $47.66 \pm 1.5$ \\
530 & $50.50 \pm 2.8$ \\
32 & $65.13 \pm 3.4$ \\
808 & $67.05 \pm 4.2$ \\
ATCC 6538P & $80.23 \pm 3.6$ \\
3 & $64.11 \pm 2.4$ \\
814 & $32.06 \pm 2.6$ \\
14 & $35.00 \pm 2.8$ \\
26 & $31.37 \pm 3.4$ \\
526 & $8.68 \pm 2.5$ \\
550 & $10.47 \pm 1.2$ \\
531 & $3.33 \pm 0.8$ \\
\hline
\end{tabular}




\subsection{Relation between Bacterial Lipid and Antibiotic Resistance}

The dendrogram reported in Figure 1B shows the taxonomic relationships between bacterial lipid profiles and the antibiotic resistance across the tested strains. The bacteria closely related were classified into two groups (red and green); it is worth noting that the four strains obtained from a hip prostheses (strain 3, 6, 32, 84), as well the two ATCC strains, four $(26,550,526,530)$ out of seven strains from the pharynges, and one strain from ulcera (14) seemed closely related in terms of lipid profiles and antibiotic resistance, whereas all the other strains were grouped together. In particular, strains 3 and 84 , both obtained from protheses, were similar in terms of lipid profile and antibiotic susceptibility (Figure 1A,B). Statistical analysis confirmed significant differences $(p<0.05)$ across the two groups on the relative abundance of the following lipids: acid 9-octadecenoic $\left(\mathrm{C}_{18: 1 \mathrm{n}-9}\right)$, acid 7-octadecenoic $\left(\mathrm{C}_{18: 1 n-7}\right)$ and iso-nonadecanoic acid (iso- $\left.\mathrm{C}_{19: 0}\right)$ (higher in the green group), eicosanoic acid $\left(\mathrm{C}_{20: 0}\right)$ (higher in the green group), henicosanoic acid $\left(\mathrm{C}_{21: 0}\right)$, and isohenicosanoic acid (iso- $\left.\mathrm{C}_{21: 0}\right)$ (higher in the green group).

\subsection{Relation between Bacterial Lipid and Cell-Surface Hydrophobicity}

Figure $1 C$ shows the dendrogram with the taxonomic relationships between bacterial lipid profiles and cell-surface hydrophobicity across the tested strains. Interestingly, the division into two groups did not vary with Figure 1C compared with Figure 1A, with the exception of strain 98, indicating no effect of cell-surface hydrophobicity on bacterial lipid profile. Statistical analysis also confirmed significant differences across the two groups as observed for antibiotic resistance.

\subsection{Relation between Bacterial Lipid, Antibiotic Resistance and Cell-Surface Hydrophobicity}

The dendrogram reported in Figure 1D shows the taxonomic relationships between bacterial lipid profiles, antibiotic resistance, and cell-surface hydrophobicity across the tested strains. The inclusion of the third parameter did not affect either the grouping or the statistical analysis compared with Figure 1B, with the exception of strain ATCC 43300.

\section{Discussion}

The present study reports the identification of lipid profiles of two ATCC strains (6538P and the methicillin-resistant 43300) and 14 clinical isolates of S. aureus and their implication on antibiotic resistance and cell-surface hydrophobicity. This was accomplished using a fast, comprehensive two-dimensional gas chromatography method in conjunction with mass spectrometry.

It is well accepted that bacterial resistance to antibiotics has become an increasing threat, especially for MRSA strains [16]. This requires both the development of novel suitable drugs to overcome antibiotic resistance, including natural compounds, as well as a better understanding of the cellular response. Yadav et al. [6] have recently demonstrated that eugenol was effective against methicillin-resistant and methicillin-sensitive Staphylococcus aureus clinical strain biofilms. The effect of cranberry extracts has also been evaluated on the growth and biofilm production of Escherichia coli and Staphylococcus sp. [17].

We have recently shown that a white grape juice (Vitis vinifera) extract was effective against Gram-positive strains, including S. aureus ATCC 6538P and S. aureus ATCC 43300 [18]. The investigation of the changes in lipid distribution in E. coli strains in response to norfloxacin has detailed a lipid response resulting from the exposure of three closely-related strains to norfloxacin [12]. The functionality of lipid profiles in bacterial membranes has been widely reported, especially for Gram-negative bacteria.

A recent study by Lopalco et al. [19] leads to the identification of unique cardiolipin and monolysocardiolipin species in Acinetobacter baumannii using combined matrix assisted laser desorption ionization-time of flight mass spectrometry (MALDI-TOF/MS) and thin-layer chromatography (TLC) analyses. A detailed knowledge on the glycerophospholipids present in the lipid extract 
of A. baumannii, including lipid classes, their proportion in membrane, and chain composition of lipids could help for the screening of possible mutants or specific membrane domains. The same authors had previously reported the presence of diphytanylglycerol analogues of phosphatidylinositol and phosphatidylglycerol in Archea bacteria [20].

Here, we demonstrated that bacterial lipid profiles varied both qualitatively and quantitatively across different strains of $S$. aureus and this reported variation affected both antibiotic resistance and cell-surface hydrophobicity. Based on the bacterial lipid profiles, we were able to identify common lipids, which were present and abundant across the strains, as well as characteristic lipids, which were not present and/or are less abundant across the strains. In particular, all clinical strains obtained from hip prostheses showed more resistance to quinolones compared to other antibiotics, which correlated with the presence of higher concentrations of $C_{18: 1 n-9}$ and iso- $C_{21: 0}$. Two of these strains (6 and 32) also showed the highest cell-surface hydrophobicity index. On the other hand, most of the strains originated from the pharynges $(526,531,550,814)$ generally possessed low cell-surface hydrophobicity indexes. These strains were grouped together with the MRSA ATCC 43300 strain and had higher amounts of the characteristic lipids anteiso-pentadecanoic acid (anteiso- $\mathrm{C}_{15: 0}$ ), iso-heptadecanoic acid (iso- $\mathrm{C}_{17: 0}$ ), acid 7-octadecenoic $\left(\mathrm{C}_{18: 1 \mathrm{n}-7}\right)$, iso-nonadecanoic acid (iso- $\left.\mathrm{C}_{19: 0}\right)$, and heneicosanoic acid $\left(C_{21: 0}\right)$. Therefore, we can hypothesize a correlation between anteiso- $C_{15: 0}$, iso- $C_{17: 0}, C_{18: 1 n-7}$, iso- $C_{19: 0}$, and $\mathrm{C}_{21: 0}$ in bacterial membranes and methicillin resistance.

The antibiotic resistance also seemed to be related to the source of infection the strains were isolated from; this could reflect their potential ability to create biofilm, whose eradication has proven rather difficult through common antibiotic treatments. The major adaptive response of the cells to an antimicrobial is to keep the fluidity of their membranes at a constant value, irrespective of the adverse environmental conditions. Such stabilization represents the main response of bacteria to membrane-active compounds or changes in the environmental conditions [21], thus preventing the loss of the physico-chemical properties of the lipid bilayer [22]. Mishra and Bayer [23] compared the lipid composition of daptomycin-susceptible and resistant MRSA; the results confirmed that daptomycin-resistant strains exhibited significantly reduced phosphatidylglycerol and carotenoid content.

Variations of external conditions, such as temperature, $\mathrm{pH}$, ethanol concentration, and osmolarity, as well as the presence of compounds affecting the microbial growth, with potential transition to the stationary phase, could result in the alteration of the fatty acid content controlling the membrane viscosity $[8,24]$.

In particular, the increase of lipid unsaturation has been reported for several microbial cells as a consequence of the decrease of growth temperature; this effect seems related to the fatty acid synthesis mechanism utilized by the cell [25].

Fozo et al. [26] suggested that monounsaturated membrane fatty acids are necessary to maintain a $\mathrm{pH}$ across the membrane and an increase in fatty acid length within the cell membrane is associated to increase survival in acidic environments.

Di Pasqua et al. [27] have demonstrated that addition of antimicrobial compounds such as thymol, carvacrol, limonene, cinnaldeyde, and eugenol in the growing media of Escherichia coli strain O157:H7, Salmonella enterica, Pseudomonas aeruginosa, Brochothrix thermosphacta, and Staphylococcus aureus altered the fatty acid profiles of the strains. These findings could explain the changes in bacterial profiles shown in the present work in relation to antibiotic resistance. Addition of a sublethal concentration of the antimicrobial compounds resulted in an adaptation mechanism for the cells to maintain membrane structure and function [27].

It is well established that transport across the bacterial cell membranes is affected by their phase transition temperature [28]. The transport of branched-chain amino acids in Pseudomonas aeruginosa [29] requires phospholipids and depends on their acyl-chain length. 


\section{Methods}

\subsection{Microbial Strains and Culture Conditions}

The following strains were obtained from an in-house culture collection (University of Messina, Messina, Italy): S. aureus ATCC 6538P, S. aureus ATCC 43300, seven clinical strains of S. aureus obtained from the pharynges (strains 26, 526, 530, 531, 550, 808, 814), two clinical strains of $S$. aureus obtained from duodenal ulcers (strains 8,14 ), four clinical strains of $S$. aureus obtained from hip prostheses (strains $3,6,32,84$ ), one clinical strain of $S$. aureus obtained from the conjunctiva (strain 98).

Strains were cultured in Muller Hinton Broth (MHB, Oxoid, CM0405) at $37{ }^{\circ} \mathrm{C}(24 \mathrm{~h})$ and cells washed three times in filtered phosphate-buffered saline (PBS) before lipid analysis.

\subsection{Analysis of Bacterial Lipid Profiles}

Sample preparation of bacterial lipid profiles were performed as previously reported [14]. Briefly, bacterial lysis and transesterification of the fatty acids (FAs) were carried out with a simple one-step method. The methylated esters solution was then directly injected into the GC systems. The analyses were performed in triplicate.

The GC-MS and GC-FID runs were carried out on two parallel GC-QP2010 and GC2010 instruments (Shimadzu, Kyoto, Japan). The GC column used was a $30 \mathrm{~m} \times 0.25 \mathrm{~mm}$ i.d. $\times 0.25 \mu \mathrm{m} \mathrm{d}_{\mathrm{f}}$ Supelcowax-10 column (Sigma-Aldrich/Supelco, Bellefonte, PA, USA). Helium was used as the carrier gas at a constant linear velocity of $30.0 \mathrm{~cm} / \mathrm{s}$ corresponding to an inlet pressure of $94.2 \mathrm{kPa}$ for GC-MS and $97.4 \mathrm{kPa}$ for GC-FID. Injection volume: $2 \mu \mathrm{L}$, split 10:1. The temperature program was the same in both analysis types: $50^{\circ} \mathrm{C}$ to $280{ }^{\circ} \mathrm{C}$ at $3{ }^{\circ} \mathrm{C} / \mathrm{min}$, held for $5 \mathrm{~min}$.

The GC-MS ion source temperature was set at $200^{\circ} \mathrm{C}$; the interface temperature, $250{ }^{\circ} \mathrm{C}$. The scan range was set to $m / z$ 40-360, with a scanning rate of $1666 \mathrm{amu} / \mathrm{s}$. The LIPIDS Mass Spectral Database (Shimadzu) was used for peak assignment, applying two filters, i.e., the spectrum similarity match over $85 \%$ and linear retention index (LRI) (related to a $\mathrm{C}_{4}-\mathrm{C}_{24}$ fatty acid methyl esters, FAMEs mixture) agreement in the \pm 10 range.

The FID temperature was set at $280{ }^{\circ} \mathrm{C}$ (sampling rate $40 \mathrm{~ms}$ ) and gas flows were $40 \mathrm{~mL} / \mathrm{min}$ for hydrogen and $400 \mathrm{~mL} / \mathrm{min}$ for air.

The data handling was supported using GCMS solution ver. 2.6 and GC solution software (version 2.43, Shimadzu) for GC-MS and GC-FID analysis, respectively.

All the reagents, as well as the bacterial fatty acid methyl esters (BAMEs), were purchased from Millipore Sigma/Supelco (Bellefonte, PA, USA).

\subsection{Susceptibility Assays}

The agar diffusion test (Kirby-Bauer antibiotic test) was used to investigate the extent to which the tested bacteria were affected by the following antibiotics: oxacillin $(1 \mu \mathrm{g})$, clarithromycin $(15 \mu \mathrm{g})$, levofloxacin $(5 \mu \mathrm{g})$, cefoxitin $(30 \mu \mathrm{g})$, vancomycin $(30 \mu \mathrm{g})$, teicoplanin $(30 \mu \mathrm{g})$, tetracycline $(30 \mu \mathrm{g})$, erythromycin $(15 \mu \mathrm{g})$, gentamicin $(10 \mu \mathrm{g})$, clindamycin $(2 \mu \mathrm{g})$, trimethoprim-sulfamethoxazole $(25 \mu \mathrm{g})$, rifampicin $(30 \mu \mathrm{g})$, linezolid $(10 \mu \mathrm{g})$, benzylpenicillin (1 UI). The zone of inhibition $(\mathrm{mm})$ was measured and recorded according to The European Committee on Antimicrobial Susceptibility Testing (EUCAST) [15]. The assay was performed in triplicate. The minimum inhibitory concentrations (MIC) and the minimum bactericidal concentrations (MBC) of vancomycin and teicoplanin against all tested strains were determined using a broth microdilution according to the Clinical and Laboratory Standards Institute [30]. MIC values were defined as the lowest extract concentrations showing no bacterial growth after the incubation time. MBCs were determined by seeding an inoculum $(20 \mu \mathrm{L})$ derived from clear MIC wells onto Mueller-Hinton agar (MHA, Oxoid) plates. The MBC was defined as the lowest extract concentration, which killed $99.9 \%$ after $24 \mathrm{~h}$ incubation at $37^{\circ} \mathrm{C}$. All assays were performed in triplicate. 


\subsection{Cell-Surface Hydrophobicity}

The cell-surface hydrophobicity of $S$. aureus strains was measured as described by Martin et al. [31]. Bacterial cells, grown overnight in MHB medium at $37^{\circ} \mathrm{C}$, were centrifuged, washed three times, and suspended in sterile saline $(0.85 \%)$ until their optical density was 0.3 at $600 \mathrm{~nm}$. The cell suspension $(6 \mathrm{~mL})$ was thereafter placed in tubes, where toluene $(1 \mathrm{~mL})$ was added. The tubes were uniformly mixed for $2 \mathrm{~min}$ and allowed to equilibrate at room temperature for $10 \mathrm{~min}$. After separation of the toluene phase from the aqueous phase, the optical density (OD) of the aqueous phase was determined spectrophotometrically at $600 \mathrm{~nm}$. The hydrophobicity index (HPBI) was calculated as follows:

$$
\frac{\mathrm{OD}(\text { initial })-\mathrm{OD}(\text { final })}{\mathrm{OD}(\text { initial })} \times 100
$$

\subsection{Data Analysis}

Analytical data were processed using the statistical JMP7 for SAS software (version 7, SAS Institute Inc., Cary, NC, USA). All analyses were performed in triplicate and repeated at least three times $(n=3)$. Data were recorded as mean \pm standard deviation (SD). Cluster analysis was performed, using all the variables studied, through multivariate analysis by Ward's method.

\subsection{Statistical Analysis}

A cluster analysis was performed to identify groups of bacteria for each feature (only lipids, lipids + antibiotic susceptibility profile, lipids + hydrophobicity, lipids + antibiotic susceptibility profile + hydrophobicity), such that two groups have been identified for each category. Based on the cluster analysis results, a comparison between groups was obtained. Examined variables were not normally distributed, such as verified via the Kolmogorov Smirnov test; consequently, the non-parametric approach was used. The Mann-Whitney test was applied in order to identify the variables either discriminating or common to the examined groups.

Statistical analyses were performed using SPSS 17.0 for Windows package (IBM, Armonk, NY, USA). For statistical significance, $p<0.05$ (two-sided) was considered significant.

\section{Conclusions}

The results of the present study indicate a potential correlation between the lipid profile of Gram-positive strains of S. aureus, site of infection, antibiotic resistance, and cell-surface hydrophobicity. This was achieved using a GC-MS method to identify fatty acids in bacterial lipid extracts. Further studies will be aimed at identifying the molecular mechanisms involved in the correlation between lipid composition and antibiotic resistance.

Author Contributions: L.M. and G.M. conceived the study, P.T. and F.F. performed the fatty acid analysis, G.G., G.C., E.L.C., and C.B. carried out the microbiological assays, A.S., D.T., and A.A. performed the statistical analysis. A.S., D.T., and G.M. wrote the paper, undertook data collection, interpretation of results and edited the manuscript. All authors read and approved the final manuscript.

Funding: This work was supported by the University of Messina. The funding body was not involved in the design of the study and collection, analysis, and interpretation of data, as well as in writing the manuscript.

Conflicts of Interest: The authors declare that they have no competing interest.

\section{Abbreviations}

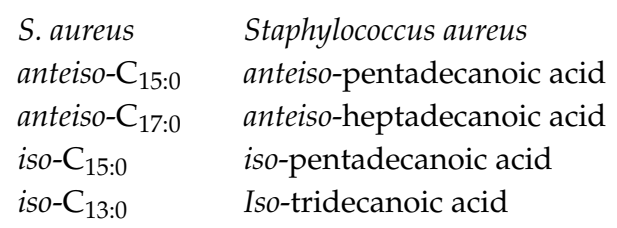




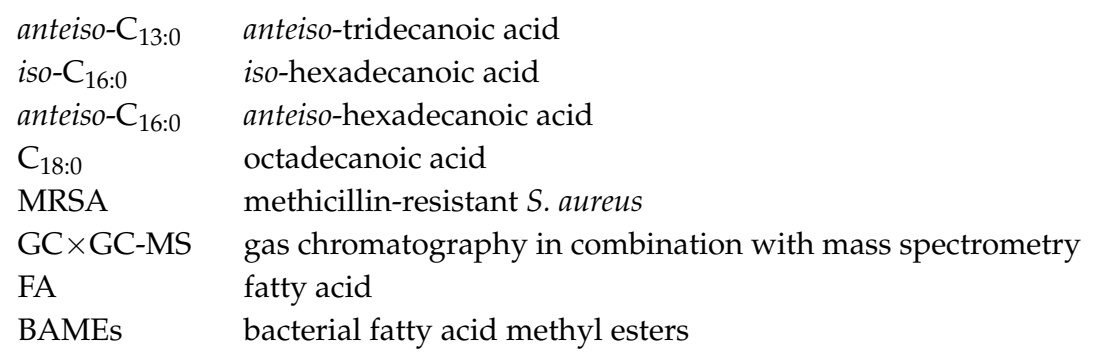

\section{References}

1. Lowy, F.D. Staphylococcus aureus infections. N. Engl. J. Med. 1998, 339, 520-532. [CrossRef] [PubMed]

2. Costerton, J.W.; Stewart, P.S.; Greenberg, E.P. Bacterial biofilms: A common cause of persistent infections. Science 1999, 284, 1318-1322. [CrossRef]

3. Maki, D.G.; Kluger, D.M.; Crnich, C.J. The risk of bloodstream infection in adults with different intravascular devices: A systematic review of 200 published prospective studies. Mayo Clin. Proc. 2006, 81, 1159-1171. [CrossRef]

4. Thornton, R.B.; Wiertsema, S.P.; Kirkham, L.A.; Rigby, P.J.; Vijayasekaran, S.; Coates, H.L.; Richmond, P.C. Neutrophil extracellular traps and bacterial biofilms in middle ear effusion of children with recurrent acute otitis media-a potential treatment target. PLOS ONE 2013, 8, e53837. [CrossRef]

5. Bisignano, C.; Filocamo, A.; Mandalari, G.; Navarra, M. Effect of a white grape (Vitis vinifera L.) juice extract on the growth and biofilm production of methicillin-resistant and sensitive Staphylococcus species. Clinic. Microb. Case Rep. 2015, 1, 016.

6. Yadav, M.K.; Chae, S.W.; Im, G.J.; Chung, J.W.; Song, J.J. Eugenol: A phyto-compound effective against methicillin-resistant and methicillin-sensitive Staphylococcus aureus clinical strain biofilms. PLoS ONE 2015, 10, e0119564. [CrossRef] [PubMed]

7. Shireen, T.; Singh, M.; Dhawan, B.; Mukhopadhyay, K. Characterization of cell membrane parameters of clinical isolates of Staphylococcus aureus with varied susceptibility to alpha-melanocyte stimulating hormone. Peptides 2012, 37, 334-339. [CrossRef] [PubMed]

8. Denich, T.J.; Beaudette, L.A.; Lee, H.; Trevors, J.T. Effect of selected environmental and physico-chemical factors on bacterial cytoplasmic membranes. J. Microbiol. Methods 2003, 52, 149-182. [CrossRef]

9. Sampathkumar, B.; Khachatourians, G.G.; Korber, D.R. Treatment of Salmonella enterica serovar Enteritidis with a sublethal concentration of trisodium phosphate or alkaline $\mathrm{pH}$ induces thermotolerance. Appl. Environ. Microbiol. 2004, 70, 4613-4620. [CrossRef]

10. Yuk, H.G.; Marshall, D.L. Adaptation of Escherichia coli O157: H7 to $\mathrm{pH}$ alters membrane lipid composition, verotoxin secretion, and resistance to simulated gastric fluid acid. Appl. Environ. Microbiol. 2004, 70, 3500-3505. [CrossRef] [PubMed]

11. Yehia, H.M.; Hassanein, W.A.; Ibraheim, S.M. Studies on molecular characterizations of the outer membrane proteins, lipids profile, and exopolysaccharides of antibiotic resistant strain Pseudomonas aeruginosa. Biomed. Res. Int. 2015, 651464.

12. Schenk, E.R.; Nau, F.; Thompson, C.J.; Tse-Dinh, Y.C.; Fernandez-Lima, F. Changes in lipid distribution in E. coli strains in response to norfloxacin. J. Mass Spectrom. 2015, 50, 88-94. [CrossRef] [PubMed]

13. Díaz, L.; Hoare, A.; Soto, C.; Bugueño, I.; Silva, N.; Dutzan, N.; Venegas, D.; Salinas, D.; Pérez-Donoso, J.M.; Gamonal, J.; et al. Changes in lipopolysaccharide profile of Porphyromonas gingivalis clinical isolates correlate with changes in colony morphology and polymyxin B resistance. Anaerobe 2015, 33, $25-32$. [CrossRef] [PubMed]

14. Purcaro, G.; Tranchida, P.Q.; Dugo, P.; La Camera, E.; Bisignano, G.; Conte, L.; Mondello, L. Characterization of bacterial lipid profiles by using rapid sample preparation and fast comprehensive two-dimensional gas chromatography in combination with mass spectrometry. J. Sep. Sci. 2010, 33, 2334-2340. [CrossRef] [PubMed]

15. The European Committee on Antimicrobial Susceptibility Testing. Breakpoint tables for interpretation of MICs and zone diameters. Version 9.0. 1 January 2019. Available online: http:/ / www.eucast.org (accessed on 21 March 2019). 
16. Doulgeraki, A.I.; Di Ciccio, P.; Ianieri, A.; Nychas, G.E. Methicillin-resistant food-related Staphylococcus aureus: A review of current knowledge and biofilm formation for future studies and applications. Res. Microbiol. 2017, 168, 1-15. [CrossRef] [PubMed]

17. LaPlante, K.L.; Sarkisian, S.A.; Woodmansee, S.; Rowley, D.C.; Seeram, N.P. Effects of cranberry extracts on growth and biofilm production of Escherichia coli and Staphylococcus species. Phytother. Res. 2012, 26, 1371-1374. [CrossRef] [PubMed]

18. Filocamo, A.; Bisignano, C.; Mandalari, G.; Navarra, M. In Vitro Antimicrobial Activity and Effect on Biofilm Production of a White Grape Juice (Vitis vinifera) Extract. Evid. Based Complement. Alternat. Med. 2015, 856243.

19. Lopalco, P.; Stahl, J.; Annese, C.; Averhoff, B.; Corcelli, A. Identification of unique cardiolipin and monolysocardiolipin species in Acinetobacter baumannii. Sci. Rep. 2017, 7, 2972. [CrossRef]

20. Lobasso, S.; Lopalco, P.; Angelini, R.; Vitale, R.; Huber, H.; Müller, V.; Corcelli, A. Coupled TLC and MALDI-TOF/MS analyses of the lipid extract of the hyperthermophilic archaeon Pyrococcus furiosus. Archaea 2012, 957852.

21. Heipieper, H.J.; Meinhardt, F.; Segura, A. The cis-trans isomerase of unsaturated fatty acids in Pseudomonas and Vibrio: Biochemistry, molecular biology and physiological function of a unique stress adaptive mechanism. FEMS Microbiol. Lett. 2003, 229, 1-7. [CrossRef]

22. Russell, N.J.; Fukunaga, N. A comparison of thermal adaptation of membrane lipids in psychrophilic and thermophilic bacteria. FEMS Microbiol. Rev. 1990, 75, 171-182. [CrossRef]

23. Mishra, N.N.; Bayer, A.S. Correlation of cell membrane lipid profiles with daptomycin resistant methicillin-resistant Staphylococcus aureus. Ant. Ag. Chemother. 2013, 57, 1082-1085. [CrossRef]

24. Russell, A.D. Potential sites of damage in micro-organisms exposed to chemical or physical agents. Soc. Appl. Bacteriol. Symp. Ser. 1984, 12, 1-18.

25. Suutari, M.; Laakso, S. Microbial fatty acids and thermal adaptation. Crit. Rev. Microbiol. 1994, 20, $285-328$. [CrossRef]

26. Fozo, E.M.; Quivey, R.G., Jr. Shifts in the membrane fatty acid profile of Streptococcus mutans enhance survival in acidic environments. Appl. Environ. Microbiol. 2004, 70, 929-936. [CrossRef] [PubMed]

27. Di Pasqua, R.; Hoskins, N.; Betts, G.; Mauriello, G. Changes in membrane fatty acids composition of microbial cells induced by addiction of thymol, carvacrol, limonene, cinnamaldehyde, and eugenol in the growing media. J. Agric. Food Chem. 2006, 54, 2745-2749. [CrossRef] [PubMed]

28. McElhaney, R.N. The effect of membrane lipids on permeability and transport in prokaryotes. In Structure and Properties of Cell Membranes; Benga, G., Ed.; CRC Press, Inc.: Boca Raton, FL, USA, 1985; Volume 2, pp. 20-51.

29. Uratani, Y.; Wakayama, N.; Hoshino, T. Effect of lipid acyl chain length on activity of sodium-dependent leucine transport system in Pseudomonas aeruginosa. J. Biol. Chem. 1987, 262, 16914-16919. [PubMed]

30. Clinical and Laboratory Standards Institute (CLSI). Clinical and Laboratory Standards Institute Performance Standards for Antimicrobial Susceptibility Testing; CLSI: Wayne, PA, USA, 2012.

31. Martin, M.A.; Pfaller, M.A.; Massanari, R.M.; Wenzel, R.P. Use of cellular hydrophobicity, slime production, and species identification markers for the clinical significance of coagulase-negative staphylococcal isolates. Am. J. Infect. Control. 1989, 17, 130-135. [CrossRef]

Sample Availability: The datasets used and/or analyzed during the current study are available from the corresponding author on reasonable request.

(C) 2019 by the authors. Licensee MDPI, Basel, Switzerland. This article is an open access article distributed under the terms and conditions of the Creative Commons Attribution (CC BY) license (http://creativecommons.org/licenses/by/4.0/). 